
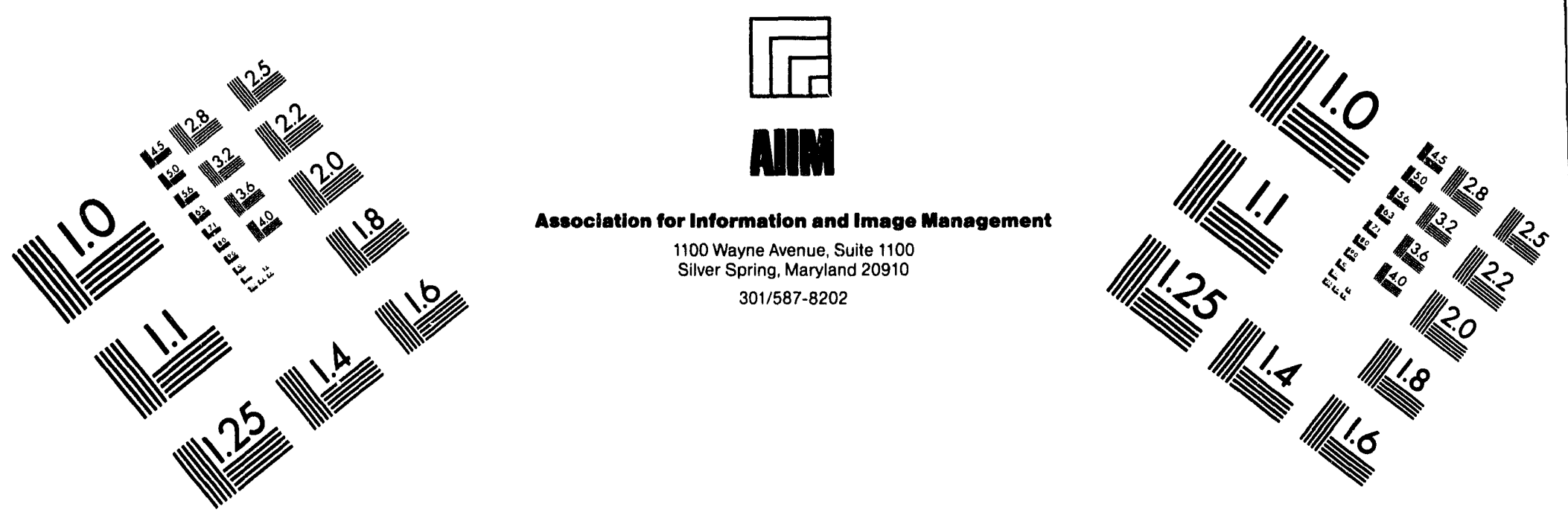

Centimeter

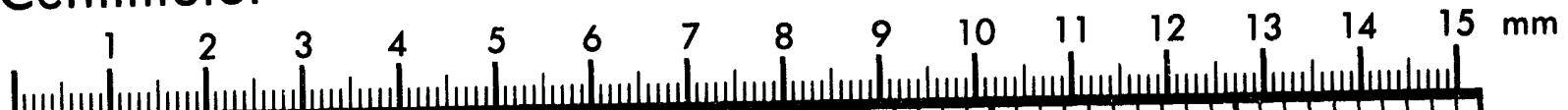

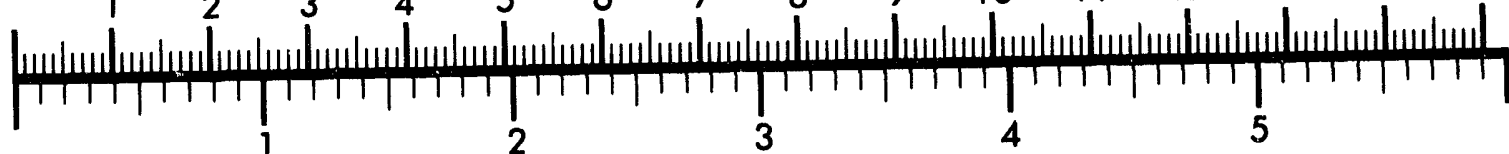
Inches
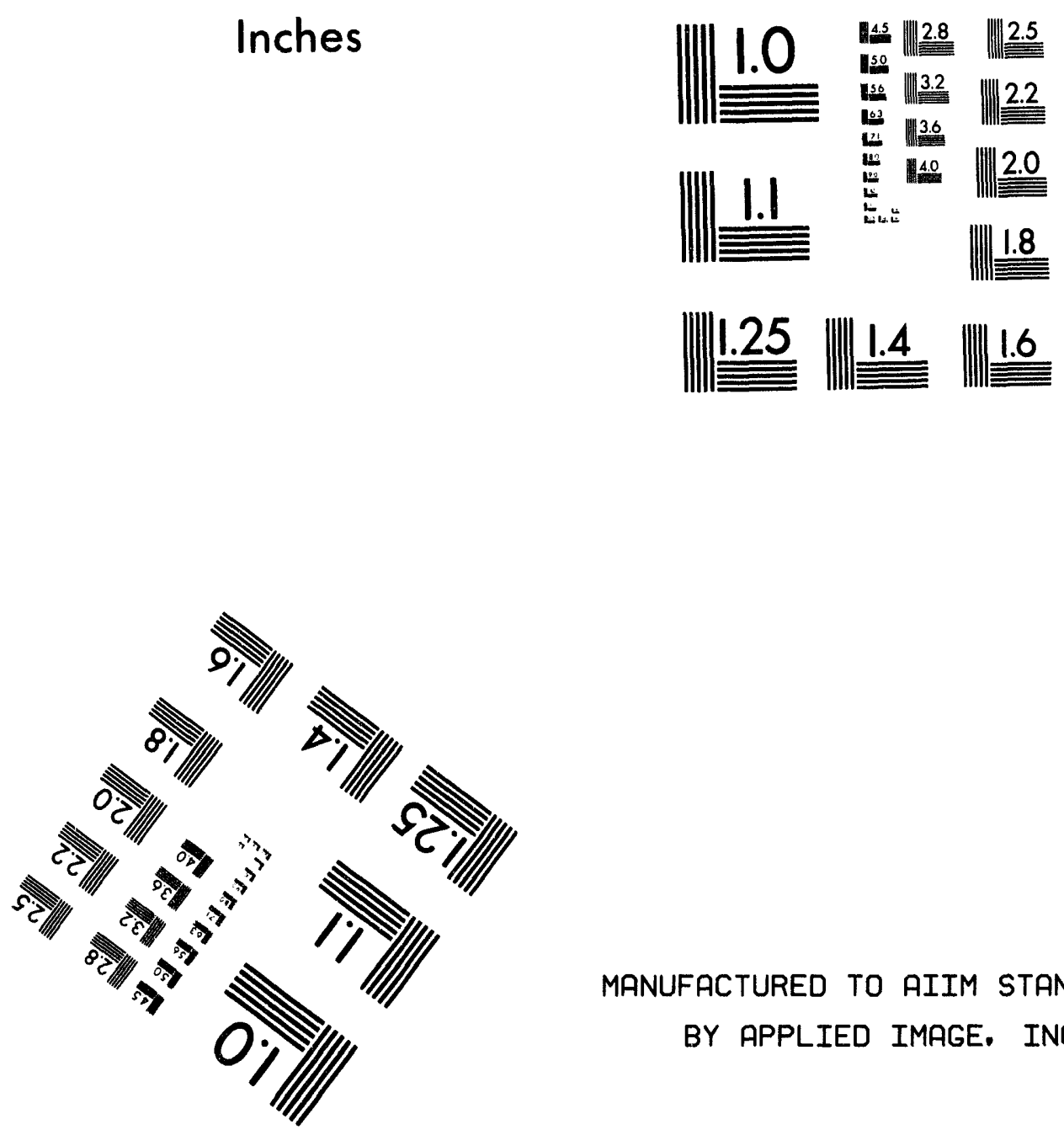

MANUFACTURED TO AIIM STANDARDS

BY APPLIED IMAGE, INC.

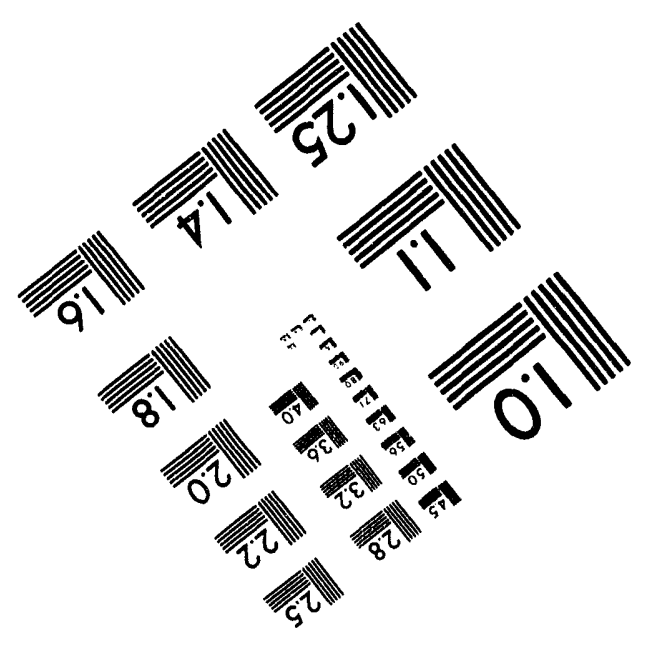



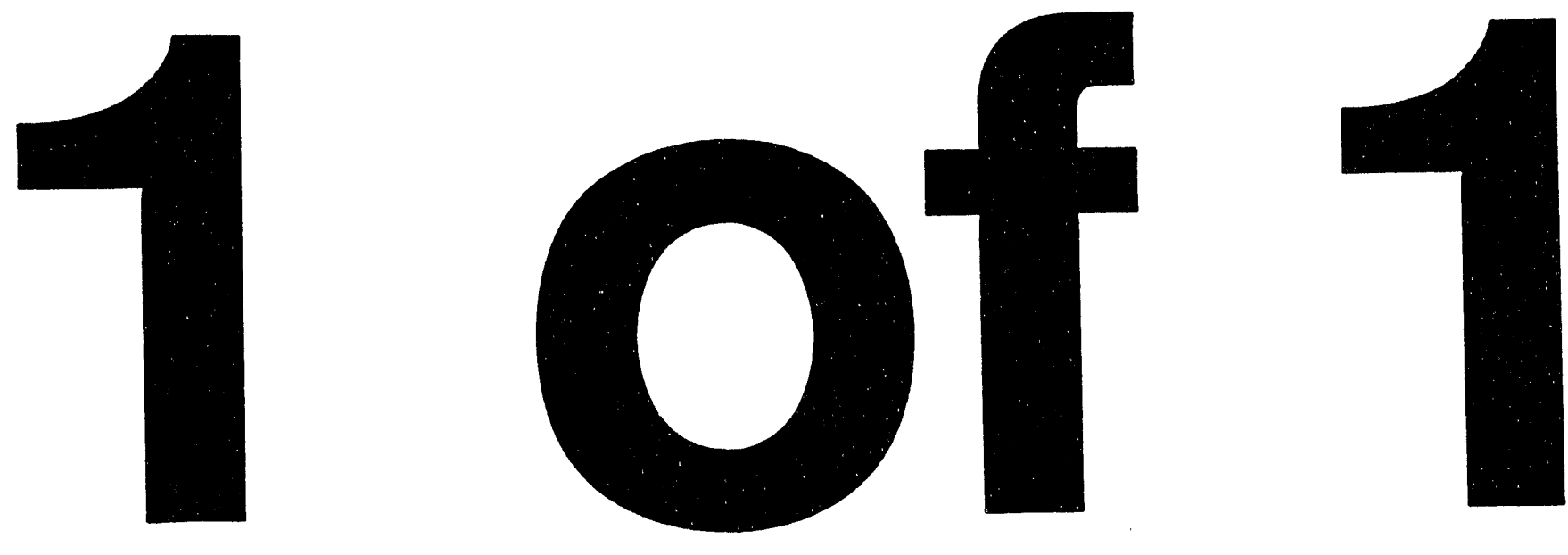


\section{A SYSTEM FOR MEASURING THE ATTENUATION OF X-RAYS BY VARIOUS MATERIALS}

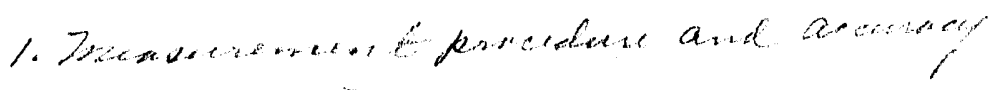

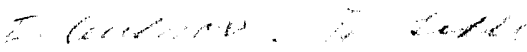

By

Leif V. Singman

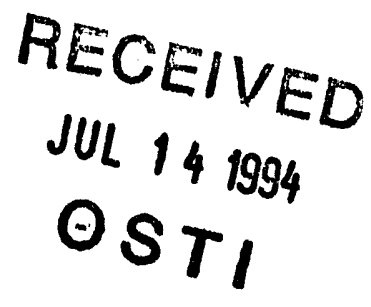

Approved for Publication

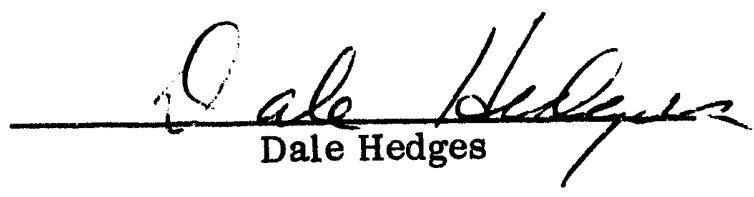

This Document is UNCLASSI FIED

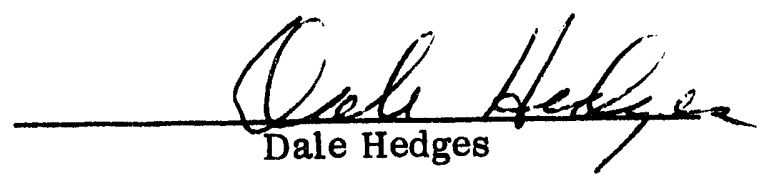

Prepared for the U. S. Atomic Energy Commission Under Contract No. AT(29-1)-1183. 
CONTENTS

Page

I. INTRODUCTION

II. CAPABILITIES AND LIMITATIONS OF SYSTEM

III. MEASUREMENT PROCEDURE

IV . MEASUREMENT ACCURACY

A. Effect of Radiation Impurities

1. Harmonics of Primary Radiation

2. Scattering of $X$-ray Continuum by

Resolving Crystal

B. Effect of Finite Energy Width of Beam

C. Effect of Detector Deadtime Losses

V. ELEMENTAL ANALYSIS USING X-RAY ABSORBTION

EDGE SPECTOMETRY
A. Theory
B. Equipment
C. Results

BIBLIOGRAPHY

\section{DISCLAIMER}

This report was prepared as an account of work sponsored by an agency of the United States Government. Neither the United States Government nor any agency thereof, nor any of their employees, makes any warranty, express or implied, or assumes any legal liability or responsibility for the accuracy, completeness, or usefulness of any information, apparatus, product, or process disclosed, or represents that its use would not infringe privately owned rights. Reference herein to any specific commercial product, process, or service by trade name, trademark, manufacturer, or otherwise does not necessarily constitute or imply its endorsement, recommendation, or favoring by the United States Government or any agency thereof. The views and opinions of authors expressed herein do not necessarily state or reflect those of the United States Government or any agency thereof.

$$
-\mathrm{ii}-
$$




\section{ILLUSTRATIONS}

1. Experimental Arrangement.

2. Pulse Height Scan with Sodium Iodide Counter.

3. Pulse Height Scan with Xenon Proportional Counter.

4. Bromine $\mathrm{K}$ Absorption Jump - Bromine in Photographic Film.

5. Silver K Absorption Jump - Silver in Photographic Film.

6. Lead L III Absorption Jump - Lead in Chevron Gasoline. 


\section{INTRODUCTION}

The Filter Attenuation Measurement System was designed by J. H. McCrary (1). It is, as its name implies, primarily intended to measure the attenuation of an $x$-ray beam by various substances. However, it can also be a very useful instrument for qualitative as well as quantitative analysis through the use of absorption edge spectometry $(2,3,4,5)$.

The essential components of the system are depicted in Fig. 1. * The brehmstrahlung originating in a tungsten target $\mathrm{x}-\mathrm{ray}$ tube is collimated and the desired energy picked out by varying the angle that the primary beam makes with the (200) set of planes in a LiF crystal. The reflected beam, which is monochromatic, passes through two collimators before being detected by a NaI counter. The sample whose transmissivity is being measured is placed between the second and third collimators.

* From reference (1). 


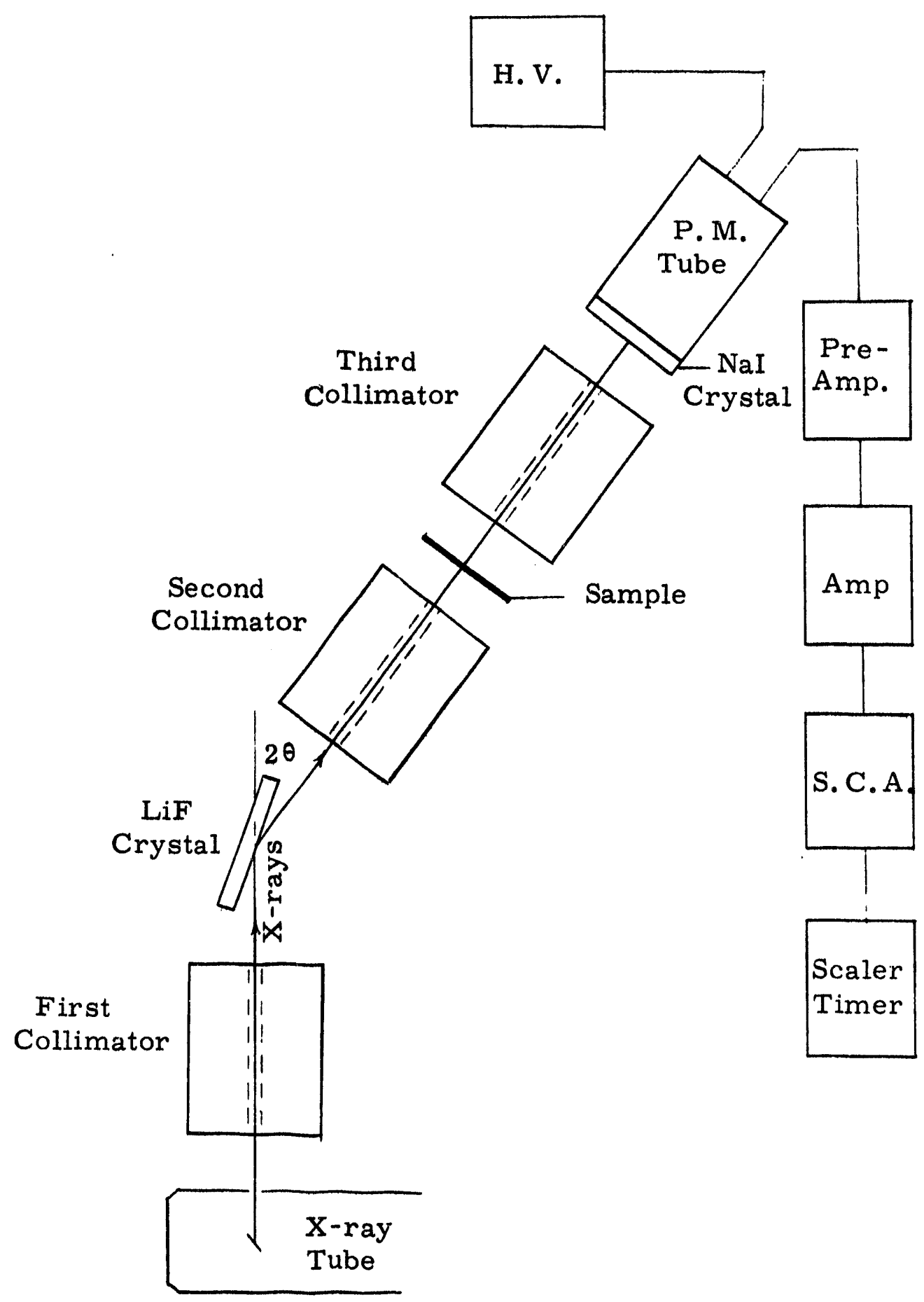

Figure 1. Experimental Arrangement 


\section{CAPABILITIES AND LIMITATIONS OF SYSTEM}

The system is designed to measure the narrow beam transmissivity of materials for radiation ranging in energy from about $5 \mathrm{kev}$ to about $30 \mathrm{kev}$. The beam flux at the low end is severely limited by the output capacity of the $x$-ray tube and by air attenuation. Add to this the heavy absorption of most materials for low energy $x$-rays and it will be easily seen that there will be a very low count rate with accompanying reduced accuracy when the filter is in place. The reduced accuracy is due to: (1) poor counting statistics; (2) fluctuation in the $\mathrm{x}$-ray beam intensity being made more critical due to the longer counting times; (3) the increased detrimental effects of hard impurities in the $x$-ray beam. The se three factors will be discussed further below. It should also be pointed out that the transmissivity is very sensitive to the thickness of the filter at low transmissivities so that if a different portion of the filter from that tested is actually used, it may lead to faulty results. 


\section{MEASUREMENT PROCEDURE}

The unattenuated beam is measured at the beginning and end of each transmission measurement in order to detect any variation of the intensity of the beam. The attenuated beam is measured with the filter in four different positions. For a constant beam intensity, differences in the four transmitted intensities would indicate nonuniformity of the thickness of the filter. The counter background measured with the shutter closed is subtracted from both the attenuated and the unattenuated beam intensities before the quotient $\frac{\mathrm{I}}{\mathrm{I}_{0}}$ is formed.

Each measurement, with the exception of background, is made for an interval long enough to allow at least 10,000 counts to be accumulated. Errors due to counting statistics would then be about one percent. Occasionally, it is necessary to settle for a lesser number of counts due to low count rates. 


\section{MEASUREMENT ACCURACY}

\section{A. Effect of Radiation Impurities}

1. Harmonics of primary radiation.

The resolving crystal not only reflects the radiation of the selected wavelength, but also the harmonics $(\lambda / 2, \lambda / 3, \ldots)$ of that wavelength if present in the output of the $x$-ray tube. These undesired higher energy components can be minimized using pulse height discrimination or completely eliminated by the use of an $x$-ray tube voltage insufficient to excite them. Although voltage discrimination severely limits the flux of the $x$-ray beam, the use of this method is necessary because of the severe errors that even minute amounts of the harder, more penetrating radiation could introduce to transmissivity measurements. Consider a beam incident on an absorber containing a one percent $\lambda / 2$ impurity. The absorption coefficient is approximately proportional to $\lambda^{3}(6)$ away from the absorption edges so that:

$$
T(\lambda) \equiv \frac{I(\lambda)}{I_{0}(\lambda)}=\exp \left[-\left(\frac{\mu}{\rho}\right) \rho t\right] \approx \exp \left[-k \lambda^{3} \rho t\right]
$$

then

$$
\frac{T\left(\frac{\lambda}{2}\right)}{T(\lambda)}=\exp \left[-\frac{7}{8} \ln T(\lambda)\right]
$$

if

$$
T(\lambda)=.01 ; \frac{T(\lambda / 2)}{T(\lambda)}=\exp \left[-\frac{7}{8} \ln (.1)\right]=7.5
$$


i.e., in the case of a one percent transmissivity, $\lambda / 2$ component is transmitted 7.5 times as readily as the $\lambda$ component with the result that it constitutes $7.5 \%$ of the transmitted beam. We would measure:

$$
\frac{I(\lambda)+I(\lambda / 2)}{I_{0}(\lambda)+I_{0}(\lambda / 2)}=.1064
$$

The measurement would be in error by $6.4 \%$. For smaller transmissivities, the presence of harmonics is even more important. From this argument it can be seen that a $\lambda / 2$ impurity of at most $.1 \%$ can be tolerated if the accuracy of the measurement is to be about one percent. That such purity is not possible using pulse height discrimination with either sodium iodide or xenon gas proportional counters can be seen from the pulse height distribution (Figs. 2 and 3). The $5 \mathrm{kev}$ peak is never completely resolved from the $10 \mathrm{kev}$ peak as long as the $\mathrm{x}$-ray tube voltage is sufficient to excite the $10 \mathrm{kev}$ radiation. The $10 \mathrm{kev}$ peak contains the majority of counts, adding to the problem of reducing this component to a negligible count rate. This is due to the shape of the output spectrum of the $x$-ray tube, the $10 \mathrm{kev}$ component being situated more nearly on the white radiation hump.

2. Scattering of X-Ray continuum by resolving crystal.

A small portion of the beam incident on the absorber will be of energies other than those selected by Braggs law. These impurities are due to Compton scattering of the white radiation from the resolving 


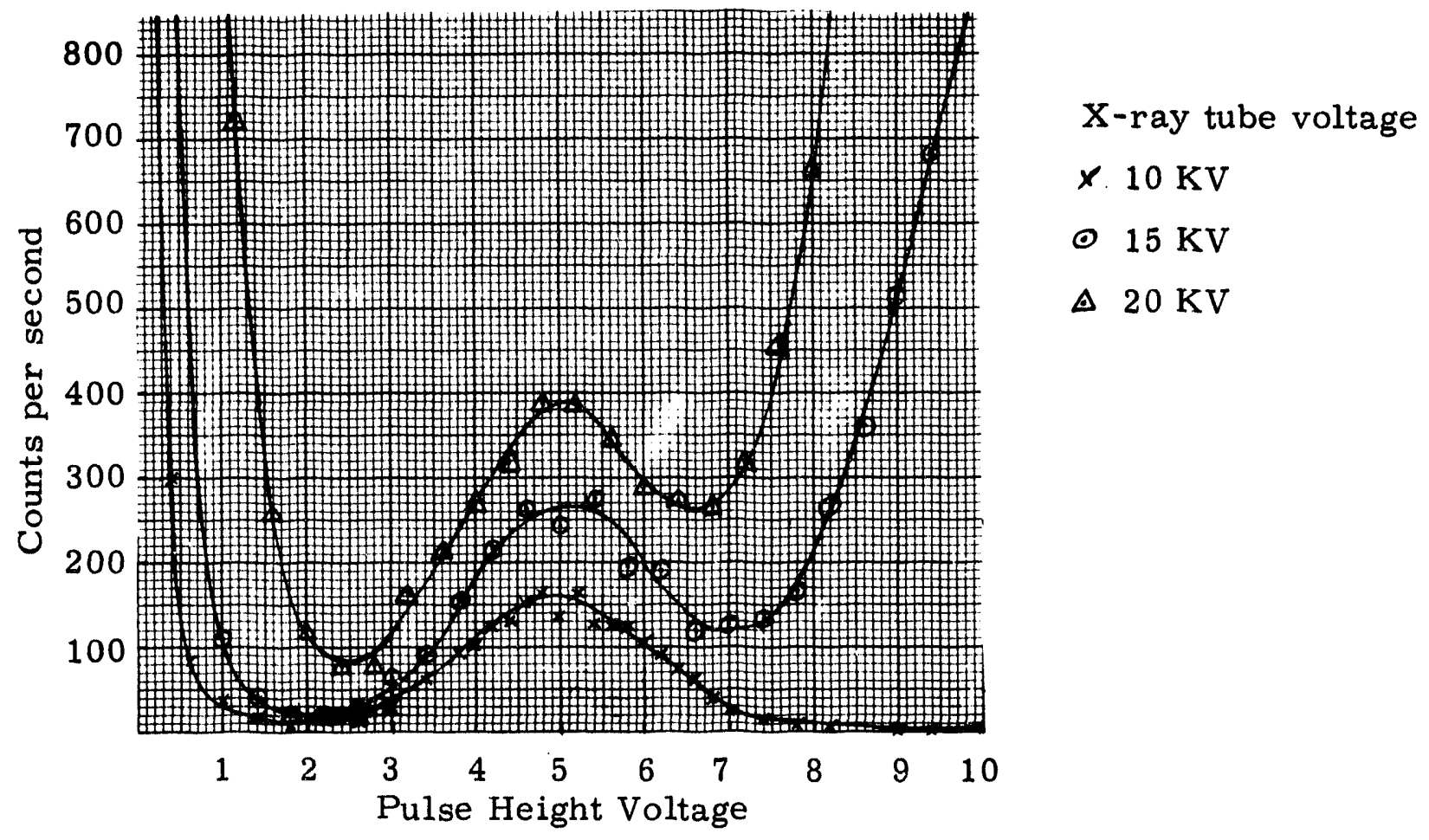

Figure 2. Pulse Height Scan - Sodium Iodide Counter

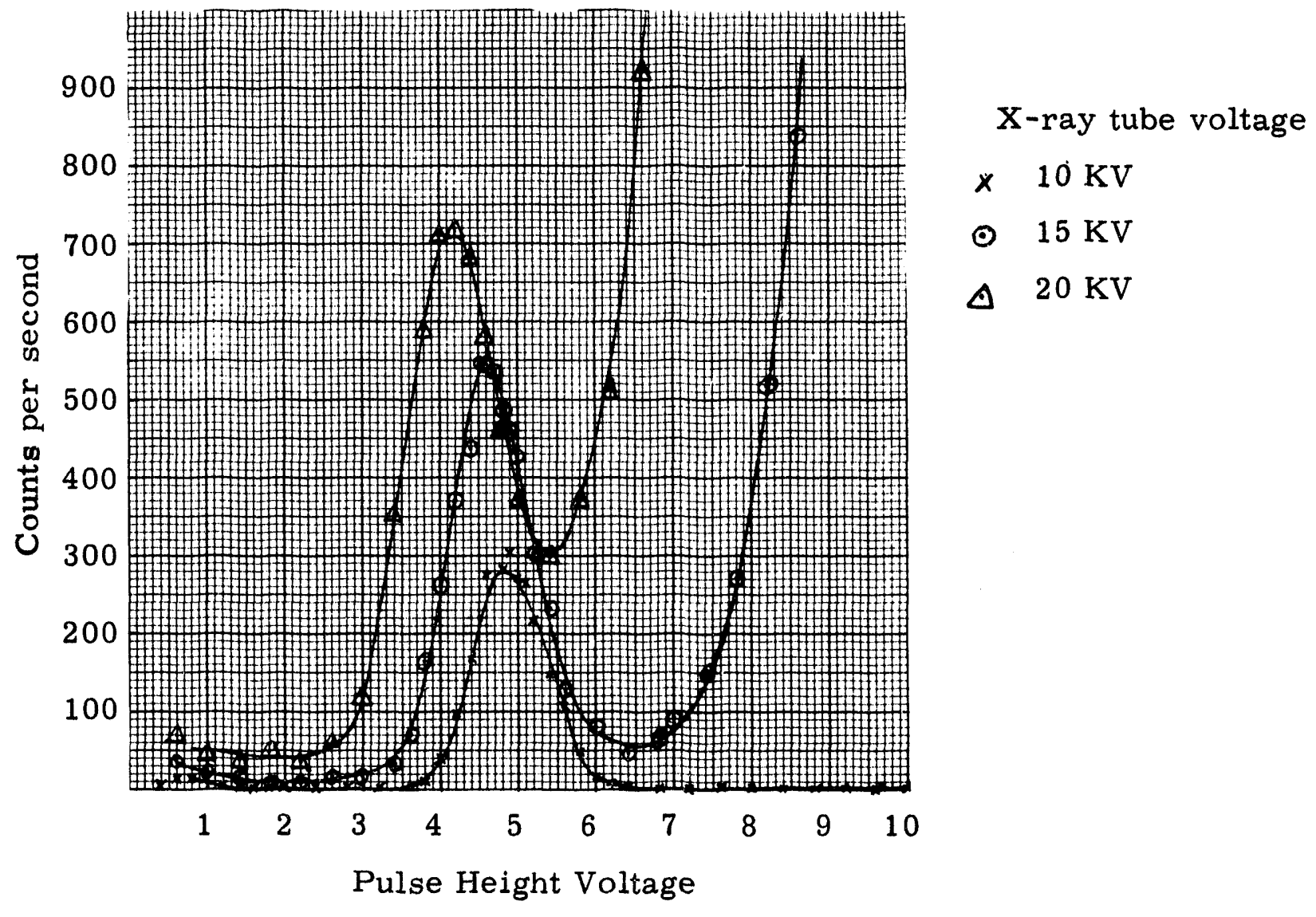

Figure 3. Pulse Height Scan - Xenon Counter 
crystal as well as scattering by crystal imperfections and thermal diffuse scattering. In order to determine if these effects were present in such degrees so as to lead to appreciable errors, the spectrum of the reflected beam was examined using a high resolution germanium detector. The examination was made for beams of several energies ranging from $5 \mathrm{kev}$ to $30 \mathrm{kev}$. The impurities on the high energy side of the main component were found to be less than one percent in all cases. With the use of pulse height discrimination, it would then be possible to further reduce the high energy impurities. It was not possible to measure the impurities on the low energy side of the main component with the same accuracy due to the counter response there. However, the softer impurities are generally much less important.

\section{B. Effect of Finite Energy Width of Beam}

Due to the finite size of the $x$-ray source, collimators and resolving crystal, the reflection angle $2 \theta$ varies slightly within the $x$-ray beam, resulting in radiation of a certain energy width. The assumption is made that the transmissivity of this beam is the same as that of a monoenergetic beam having the average band energy. This assumption is valid provided that the lower transmissivity of the less energetic half of the band is compensated for by the increased transmissivity of the more energetic half.

The expression for the width of the energy band $\Delta \mathrm{E}$, derived from Bragg's law, is 


$$
\frac{\Delta \mathrm{E}}{\mathrm{E}}=\cot \theta \Delta \theta
$$

The widest energy bands will occur for high energies since the bandwidth is proportional to the energy. Also, $\cot \theta$ will have a larger value here since high energies correspond to short wavelengths and low values of $\theta$. Let us compute the energy bandwidth for the highest energy that is likely to be used, $30 \mathrm{kev}$. Using the (200) planes in a LiF crystal and the value of $\Delta \theta$ of $.30^{\circ}$ which was obtained from measurements of the widths of characteristic lines and absorption edges we get a $\Delta E$ of $1.52 \mathrm{kev}$. Assuming the absorption coefficient is proportional to the cube of the wavelength and that the spectrum of the band is symmetric about the mean energy, the error in transmissivity due to the rays on the opposite extremes of the energy band can be computed. Let $\lambda_{0}$ be the wavelength of $30 \mathrm{kev}$ radiation and $\Delta \lambda$ be the shift in wavelength corresponding to $\Delta \mathrm{E}$, then:

$$
\frac{I}{I_{0}}=\frac{1}{2}\left\{\exp \left[-k \lambda_{0}^{3}\left(1+\frac{\Delta \lambda}{2 \lambda_{0}}\right)^{3}\right]+\exp \left[-k \lambda_{0}^{3}\left(1-\frac{\Delta \lambda}{2 \lambda_{0}}\right)^{3}\right]\right\}
$$

For a one percent transmissivity, $\frac{I}{I_{0}}=.0105$

i.e., the assumption that two rays separated in energy by $\Delta E=1.523 \mathrm{kev}$ are both of the mean energy (30 kev) would lead to an error of $5 \%$ if the transmissivity of the mean energy radiation is one percent.

In the case of rays seprated in energy by $\Delta \mathrm{E} / 2$ the error would only be $1.3 \%$. Since most of the $x$-ray photons are closer in energy than $\Delta E / 2$, the error would probably be less than $1 \%$ in the extreme 
case of a one percent transmissivity. The error would of course be less for greater transmissivities owing to the nature of the exponential function.

\section{Effect of Detector Deadtime Losses}

The loss of counts due to counter deadtime was investigated with the multiple foil technique (7). A number of aluminum foils of equal thickness was inserted in a beam of $\mathrm{Cu} \mathrm{K} \alpha \mathrm{x}$-rays and then withdrawn individually. The count rate was measured between each withdrawal. The logarithms of the count rates were plotted against the number of foils in the beam. The departure of the points from a straight line became apparent at about 10,000 counts/sec and signaled the point where the counter deadtime became significant resulting in a loss of counts. The use of count rates of up to 5,000 counts/sec would then seem to be free of large deadtime errors. 


\section{ELEMENTAL ANALYSIS USING X-RAY ABSORPTION EDGE SPECTOMETRY}

\section{A. Theory}

Elemental analysis using $\mathrm{x}$-ray absorption edges is based on the fact that the $x$-ray energy at which an absorption jump occurs is characteristic of the element and the height of the jump is related to the quantity of the element in the $x$-ray beam.

The mass absorption coefficient of a material for $\mathrm{x}$-rays of a given energy made up of $n+1$ elements can be expressed as:

$$
(\mu / \rho)_{\text {total }}=(\mu / \rho)_{E} w_{E}+\sum_{i=1}^{n}(\mu / \rho)_{i} w_{i}
$$

where $(\mu / \rho)_{E}$ is the mass absorption coefficient of the element of interest and $w_{E}$ its weight fraction; $(\mu / \rho)_{i}$ and $w_{i}$ are the corresponding quantities of the ith element.

The material will attenuate $x$-rays according to the law:

$$
I / I_{0}=e^{-(\mu / \rho)_{\text {tot }} \rho t} \text { or } \ln \left(I_{0} / I\right)=(\mu / \rho)_{\text {tot }} \rho t
$$

Let us label all quantities corresponding to the $\mathrm{x}$-ray energies just below and just above the absorption edge of the element of interest with the superscripts $B$ and $A$ respectively. Then:

$$
\left.\ln \left(I_{0} / I\right)^{B}-\ln \left(I_{0} / I\right)^{A}=[\mu / \rho)_{E}{ }^{B}-(\mu / \rho)_{E}{ }^{A}\right] \omega_{E^{\rho t}}
$$

since: 


$$
\sum_{i=1}^{n}(\mu / \rho)_{i}^{B}=\sum_{i=1}^{n}(\mu / \rho)_{i}^{A}
$$

nov:

$$
\begin{aligned}
& w_{E^{\rho t}}=\frac{W_{E}}{W_{\text {total }}} \frac{W_{\text {Total }}}{V} t=\frac{W_{E}}{A} \\
& \frac{W_{E}}{A}=\frac{\ln \left(I_{0} / I\right)^{B}-\ln \left(I_{0} / I\right)^{A}}{(\mu / \rho)_{E}^{B}-(\mu / \rho)_{E}^{A}}
\end{aligned}
$$

Thus by using measured values of $\left(\mathrm{I}_{0} / \mathrm{I}\right)^{\mathrm{B}}$ and $\left(\mathrm{I}_{0} / \mathrm{I}\right)^{\mathrm{A}}$ are tabulated values of $(\mu / \rho)_{E}^{B}$ and $(\mu / \rho)_{E}^{A}$, the quantity $W_{E} / A$ of an element present in a material can be determined.

In practice $I / I_{0}$ is measured for several energies on both sides of the absorption edge. Since $\mu$ is proportional to $\lambda^{3}$ everywhere except at absorption discontinuities, a plot of $\ln I_{0} / I$ vs $\lambda^{3}$ will result in two parallel straight lines. Values of $\ln \left(I_{0} / I\right)^{A}$ and $\ell n\left(I_{0} / I\right)^{B}$ can then be obtained by linear extrapolation.

\section{B. Equipment}

The desired $\mathrm{x}$-ray energy was obtained by resolving the white radiation from a copper target $x$-ray tube with the $(200)$ planes of a LiF crystal. The crystal was mounted on a standard GE XRD 2 spectrometer. The $2 \theta$ values were read off the protractor and the $\mathrm{x}$-ray wavelengths calculated from Bragg's law. The $\mathrm{x}$-ray energies can then be calculated from the expression:

$$
E=\frac{12,398}{\lambda}
$$


where $\lambda$ is expressed in Angstroms and the energy in electron volts. Good energy resolution of the $\mathrm{x}$-ray beam was obtained by using the line source of the $x$-ray tube, the GE lineup slit and the $.02^{\circ}$ detector slit. The resulting resolution was such that the entire absorption discontinuity took place in $.1^{\circ}(2 \theta)$. The $x$-ray tube was always operated at a voltage slightly below that necessary to generate the half wavelength.

\section{Results}

This method was used to determine the amount of $\mathrm{Ag} \mathrm{Br}$ contained in the emulsion of a certain type of photographic film from the magnitudes of the absorption jumps of both silver and bromine. A stack of 30 sheets for bromine and 100 for silver was used in order to get sufficient material for a reliable measurement. The bromine jump gave $.47 \mathrm{mg} / \mathrm{cm}^{2}$ of $\mathrm{Ag} \mathrm{Br}$ per sheet of film (Fig. 4) compared to $.46 \mathrm{mg} / \mathrm{cm}^{2}$ obtained with silver (Fig. 5). The method was also used to analyze for impurities of iron and nickel $(\sim 200 \mathrm{ppm})$ in a beryllium disc with fair $(\sim 40 \%)$ agreement with the assay provided by the manufacturer.

Finally, three grades of Chevron gasoline were analyzed for lead. The resulting graph is shown in Fig. 6. 

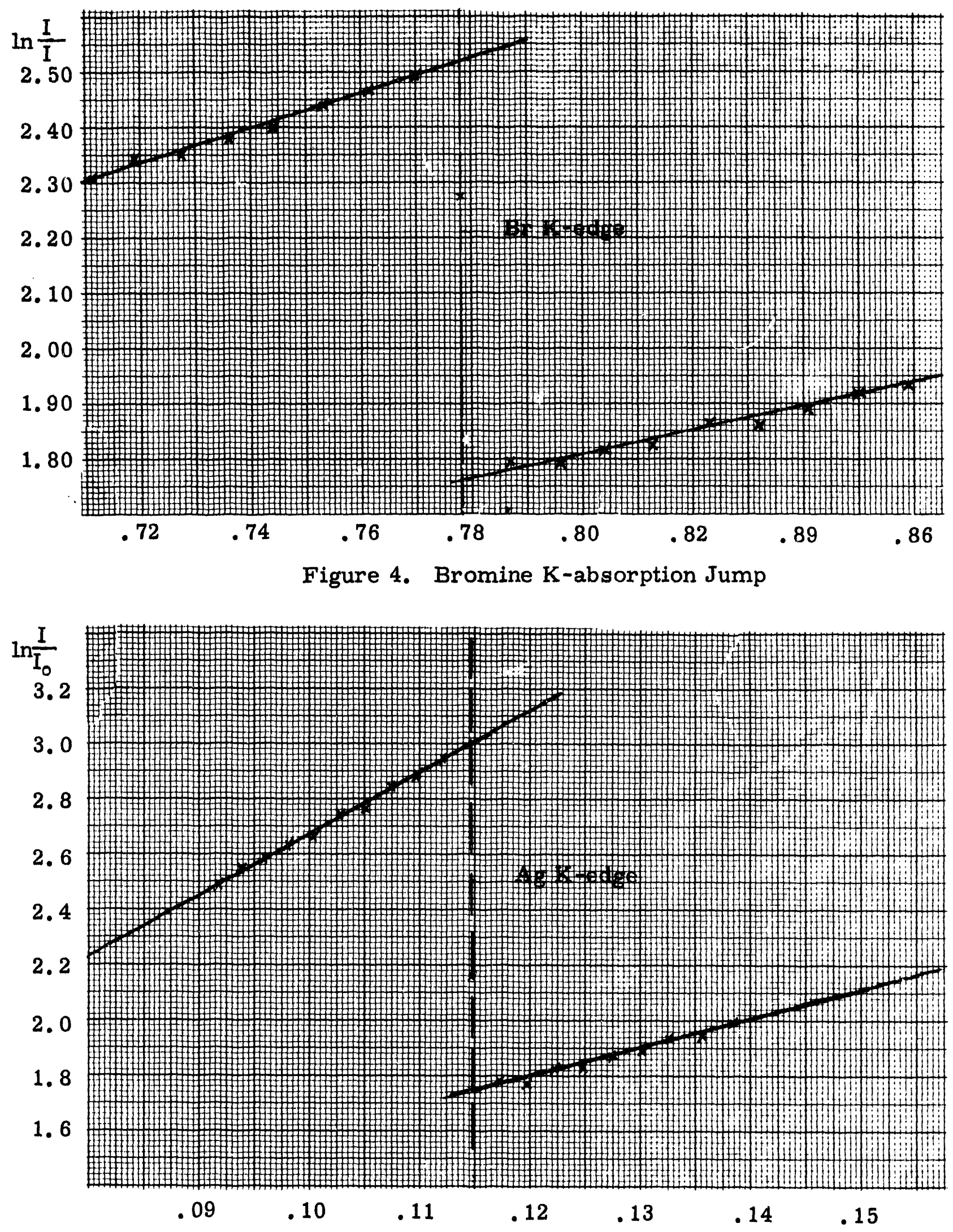

Figure 5. Silver K-absorption Jump 


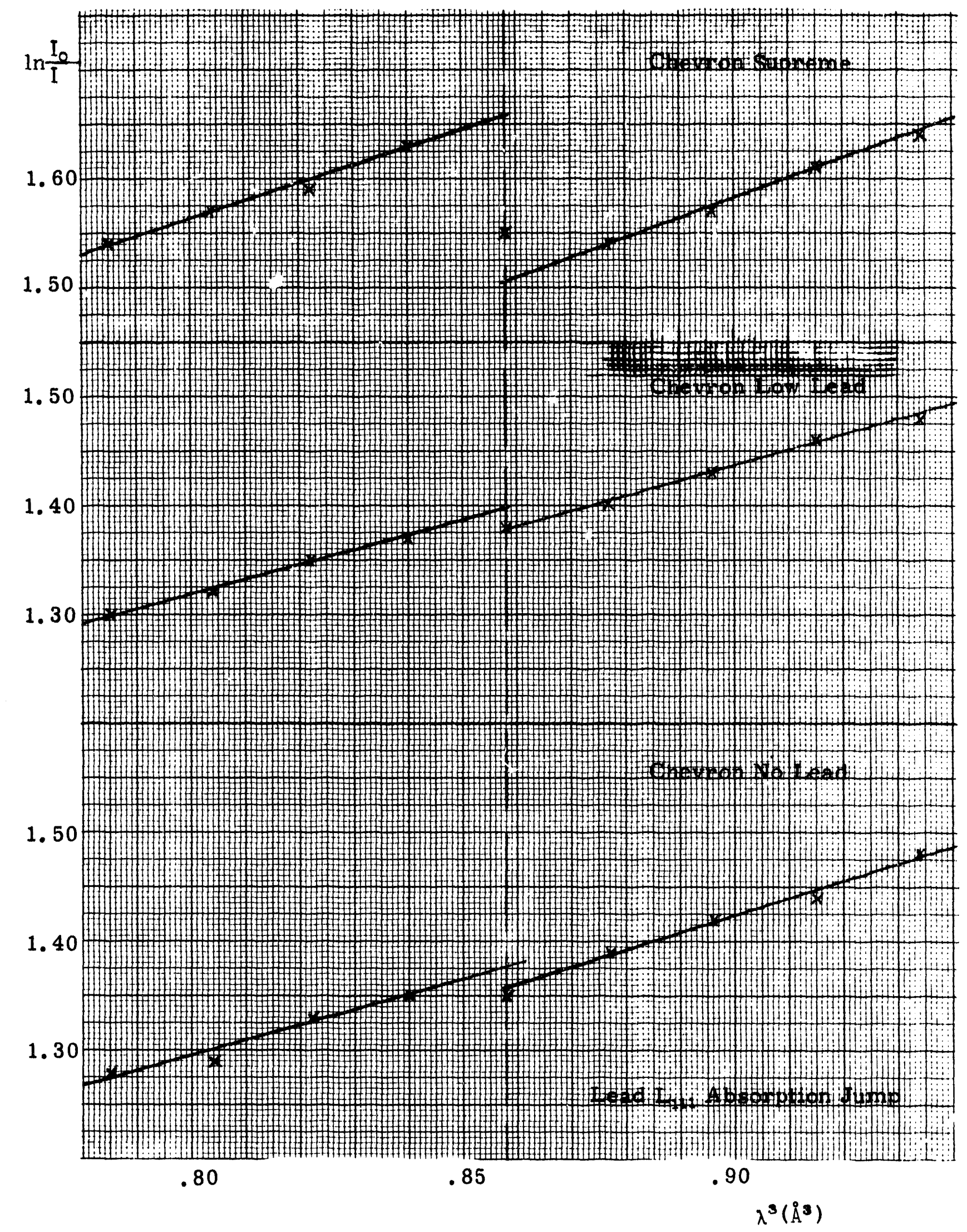

Figure 6. Lead $L_{111}$ Absorption Jump - Lead in Chevron Gasolines 


\section{REFERENCES}

1. EG\&G Proposal, Jan. 10, 1969.

2. Glocker, R., Frohnmayer, W., Ann. Physik 76, 369 (1925).

3. Ferro, A., Galotto, C. P., Ann. Chim $\underline{45}, 1234$ (1955).

4. Barieau, R. E., Anal. Chem. 29, 348 (1957).

5. Stewart, J.H., et al, Anal. Chem. 40, 27 (1968).

6. International Tables of X-Ray Crystallography, Ed. C. H. MacGillavy and G. D. Rieck, Kynoch Press, Birmingham, England, 1968.

7. Cullity, B. D. , Elements of X-Ray Diffraction, Addison-Wesley, London, England, 1956. 


\section{DISTRIBUTION}

DTIE

P. W. Rosser (2)

AEC/NVOO

J. A. Koch

R. R. Loux

R. B. Purcell

$\underline{\text { LASL }}$

J. Baran

E. W. Bennett

D. W. Lier

P. B. Lyons

L. K. Neher

E. Storm

D. R. Weatorvelt

Librsing

EG\&G-LAE

W. C. Anderson

C. R. Hatcher

Q. G. Klingler

J. J. Walker

\section{EG\&G-Las Vegas}

J. W. Churchill

A. D. Craft

J. E. Doyle

J. H. McCrary

T. R. Rottunda

J. W. Sedlmeyer

L. V. Singman (50)

E. J. Story

L. H. Ziegler

Technical Reports

EG\&G-Bedford

R. Cadwallader

$\underline{\text { Libraries-EG\&G }}$

Albuquerque

Bedford

Boston

Las Vegas

San Ramon

Santa Barbara 

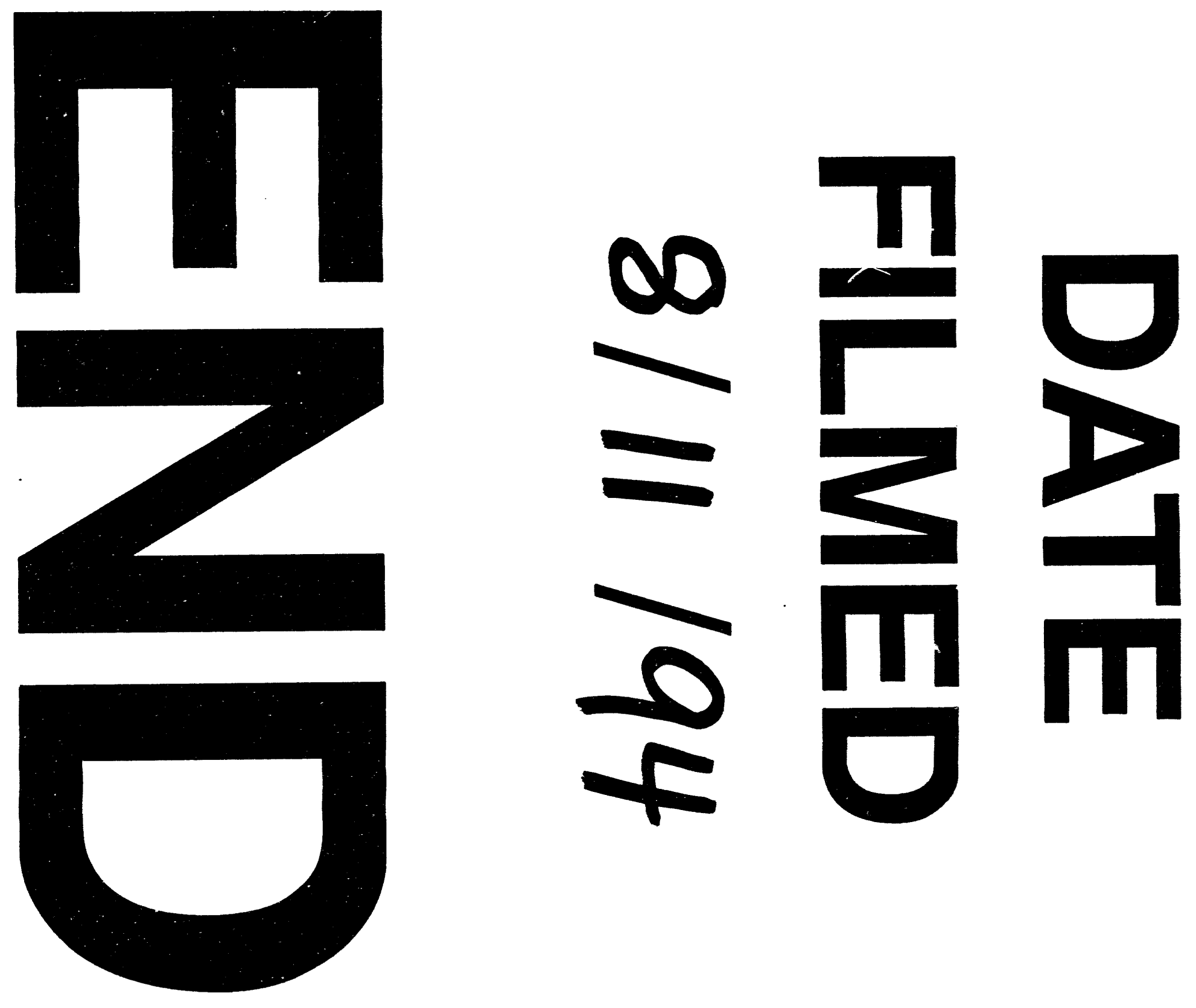
$$
\text { - }
$$ 